\title{
Neuroendoscopic Technique for Recurrent Chronic Subdural Hematoma with Small Craniotomy
}

\author{
Shinya ICHIMURA ${ }^{1,2}$, Kento TAKAHARA ${ }^{1}$, Masato NAKAYA ${ }^{1}$, Keisuke YOSHIDA ${ }^{1}$, Koji FUJII ${ }^{1}$ \\ 'Shizuoka City Shimizu Hospital, Department of Neurosurgery, Shizuoka, Japan \\ ${ }^{2}$ Kawasaki Chuo Clinic, Department of Neurosurgery, Kawasaki, Kanagawa, Japan \\ Corresponding author: Shinya ICHIMURA shinya3917@gmail.com
}

\section{ABSTRACT}

AIM: To present a case series describing an endoscopic technique with a small craniotomy for recurrent chronic subdural hematoma $(\mathrm{rCSDH})$ treatment.

MATERIAL and METHODS: A total of 17 patients with rCSDH underwent neuroendoscopic hematoma removal with a small craniotomy under local or general anesthesia. The skin incision of the initial surgery on the convexity of the skull was extended, and a burr hole was created for a small craniotomy. After the removal of the outer membrane and hematoma through a small craniotomy, the hematoma was evacuated with a suction tube using the rigid endoscope. The entire hematoma cavity circumference was irrigated, while septations and trabeculae in the hematoma were cut. After hematoma evacuation, the inner membrane was incised and removed to allow brain expansion. Postoperative follow-up was performed for at least 6 months.

RESULTS: The regrowth rate of rCSDH after the neuroendoscopy was 5.9\%. One patient with recurrent chronic subdural hematoma regrowth required neuroendoscopy again, but no re-recurrence was observed for the next 6 months. All cases were successfully managed using this technique and the postoperative seizure rate was $23.5 \%$.

CONCLUSION: This neuroendoscopic technique with a small craniotomy could be useful for recurrent chronic subdural hematoma because the hematoma and septations can be visualized and evacuated along the entire circumference of the hematoma cavity, and the inner membrane can be torn to allow brain expansion.

KEYWORDS: Chronic subdural hematoma, Neuroendoscopy, Recurrence, Small craniotomy

\section{INTRODUCTION}

$\mathrm{T}$ The incidence of chronic subdural hematoma (CSDH) increases with increasing age and the widespread use of antithrombotic agents (26). Burr-hole surgery with closed-system drainage is the most commonly performed surgery for $\operatorname{CSDH}(1,9,26,32,33,37,38)$. The rate of recurrent $\mathrm{CSDH}$ is $10 \%-15 \%(4,16,25,28,30,33,35,37)$. A total of $5 \%-$ $30 \%$ of patients with $\mathrm{CSDH}$ who undergo surgery require reoperation $(33,38)$, and $24 \%$ of these patients experience a secondary recurrence that demands further surgery (32). Although it is not widely used, endoscopic evacuation for $\mathrm{CSDH}$ is an established technique $(7,26)$. We present a case series describing an endoscopic technique with a small craniotomy for CSDH treatment.

\section{MATERIAL and METHODS}

External drainage using burr-hole craniotomy under local anesthesia was performed for the initial CSDH treatment in our hospital. The external drainage tube was removed within a day of hematoma drainage. After the initial surgery, endoscopic hematoma removal with a small craniotomy was performed in 17 cases of $\mathrm{rCSDH}$ from November 2016 to January 2019 (Table I). Our criteria for rCSDH surgery included the emergence or worsening of symptoms (headache,
Shinya ICHIMURA (10): 0000-0003-1950-9117 Kento TAKAHARA (D) : 0000-0002-6000-2513

Masato NAKAYA (1) : 0000-0003-1838-9731
Keisuke YOSHIDA (1) : 0000-0003-0764-6413

Koji FUJII (D) : 0000-0003-0567-4496 
Ichimura S. et al: Neuroendoscopy for rCSDH

Table I: Summary of Patients who Underwent Neuroendoscopic Removal of Recurrent Chronic Subdural Hematoma Using Small Craniotomy

\begin{tabular}{cccccc}
\hline Patients & Age(year)/Sex & Side & Medication & Period of recurrence (day) & Maximum diameter (mm) \\
\hline 1 & $75 / \mathrm{F}$ & $\mathrm{R}$ & - & 5 & 26 \\
\hline 2 & $76 / \mathrm{M}$ & $\mathrm{L}$ & Clopidogrel & 15 & 15 \\
\hline 3 & $86 / \mathrm{M}$ & $\mathrm{R}$ & Warfarin & 20 & 35 \\
\hline 4 & $90 / \mathrm{F}$ & $\mathrm{L}$ & - & 15 & 17 \\
\hline 5 & $78 / \mathrm{M}$ & $\mathrm{L}$ & Warfarin & 21 & 18 \\
\hline 6 & $62 / \mathrm{M}$ & $\mathrm{R}$ & - & 15 & 19 \\
\hline 7 & $91 / \mathrm{M}$ & $\mathrm{R}$ & - & 16 & 22 \\
\hline 8 & $85 / \mathrm{F}$ & $\mathrm{R}$ & - & 5 & 37 \\
\hline 9 & $89 / \mathrm{M}$ & $\mathrm{L}$ & - & 38 & 18 \\
\hline 10 & $80 / \mathrm{M}$ & $\mathrm{L}$ & Rivaroxaban & 14 & 25 \\
\hline 11 & $87 / \mathrm{M}$ & $\mathrm{L}$ & - & 16 & 18 \\
\hline 12 & $88 / \mathrm{M}$ & $\mathrm{L}$ & - & 17 & 20 \\
\hline 13 & $88 / \mathrm{M}$ & $\mathrm{R}$ & - & 36 & 18 \\
\hline 14 & $86 / \mathrm{M}$ & $\mathrm{L}$ & - & 9 & 27 \\
\hline 15 & $96 / \mathrm{M}$ & $\mathrm{L}$ & - & 38 & 12 \\
\hline 16 & $77 / \mathrm{F}$ & $\mathrm{L}$ & - & 14 & 20 \\
\hline 17 & $74 / \mathrm{M}$ & $\mathrm{L}$ & - & 9 & 33 \\
\hline$R$
\end{tabular}

R: Right, L: Left.

hemiparesis, and aphasia) and hematoma regrowth as observed in the postoperative imaging. A total of 13 males and 4 females with an average age of 82.8 years (range, 62-96 years) were included. There were 6 right-sided and 11 left-sided recurrent CSDHs. Four patients were undergoing treatment with antiplatelet or anticoagulant agents. The average period between initial CSDH and recurrence was 17.8 days (range, 5-38 days). The maximum diameter of the hematoma ranged from 15-37 mm (average, $22.4 \mathrm{~mm}$ ). All patients underwent unilateral surgery. Consent was obtained from all patients and their families. The study was reviewed and approved by ethical committee board.

\section{Neuroendoscopic Technique}

Surgery was performed under local or general anesthesia. The skin incision of the initial surgery on the convexity of the skull was extended to approximately $5 \mathrm{~cm}$, and a burr hole was created to perform a small craniotomy that measured approximately $4 \mathrm{~cm}$ (Figure 1). After the removal of the outer membrane and hematoma, a rigid neuroendoscope (Olympus, Tokyo, Japan) was inserted. The hematoma was evacuated using a suction tube and the entire circumference of the hematoma cavity was irrigated, while the septations, which formed multiple loculated compartments in the hematoma) were cut (Figure 2). The visible hematoma was cleared using suction. After the hematoma evacuation, the inner membrane was incised and removed to allow for brain expansion (Figure 3). Prior to securing the bone flap using two titanium plates (Lorenz $^{\circledR}$ plating system, Biomet, Jacksonville, USA) and autologous bone dust (17), the draining catheter was inserted in the hematoma cavity under endoscopic guidance (Figure 4).

\section{RESULTS}

Patients were operated under general or local anesthesia (11/17 and 6/17, respectively) (Table II). Septations were intraoperatively observed in 10/17 patients (58.8\%). The postoperative follow-up period was for an average of 11.5 months (range, 6-23 months). One patient developed rCSDH and required neuroendoscopy again after 23 days; however, no re-recurrence was observed for the next 6 months. All patients were successfully managed with this neuroendoscopic technique, and none of the patients experienced cosmetic skin depression. Postoperative seizures occurred in 4/17 patients (23.5\%); of these, 3 patients with left-sided hematoma experienced focal seizures presenting with aphasia, while one patient experienced generalized seizures. Postoperative seizures in all patients were controlled using an anticonvulsant, such as levetiracetam or lacosamide. 


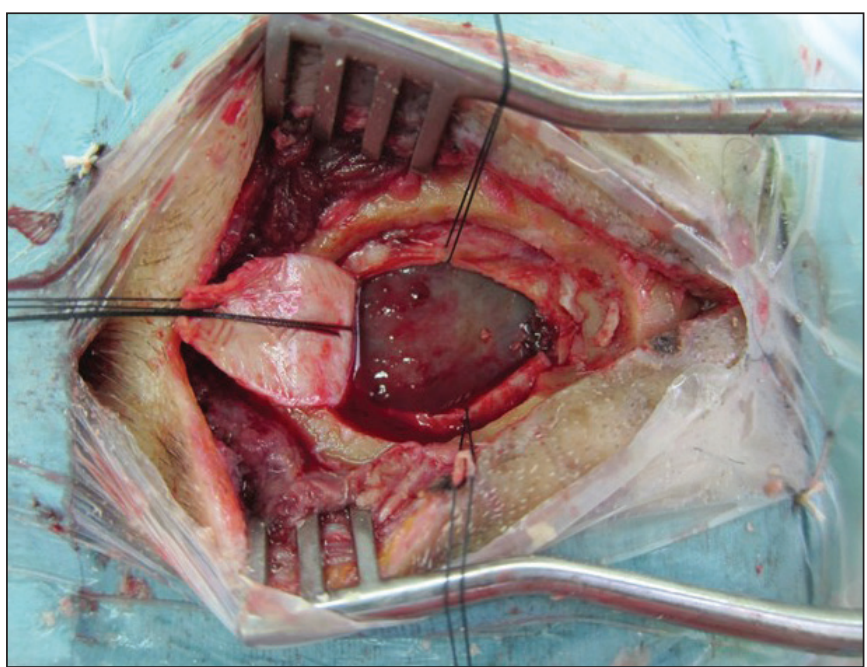

Figure 1: A small craniotomy of approximately $3 \mathrm{~cm}$ is performed to insert the neuroendoscope and neurosurgical instruments.

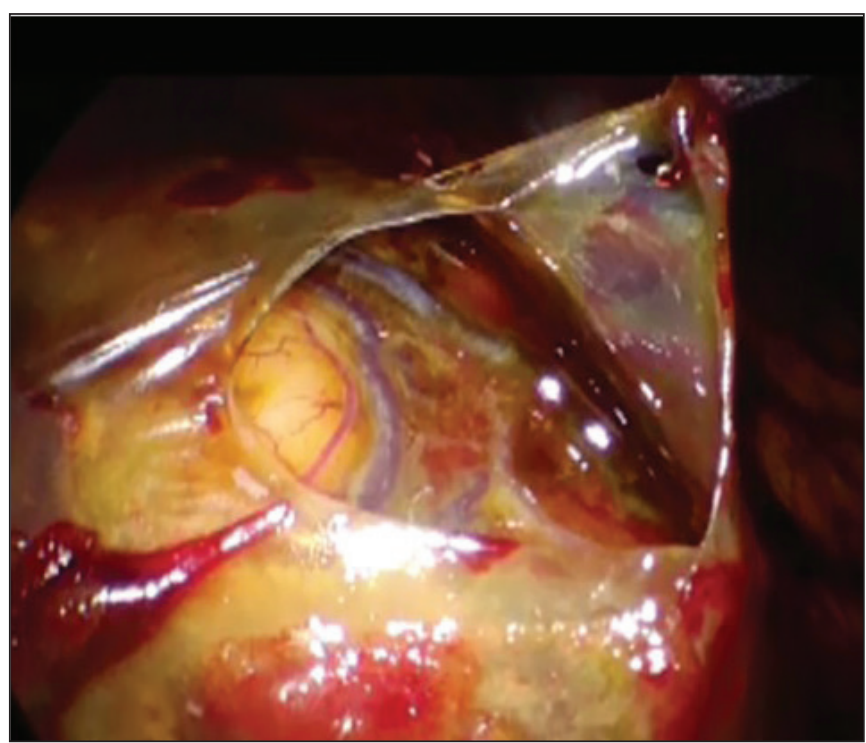

Figure 3: The inner membrane of the subdural hematoma was incised and removed to allow for brain expansion.

\section{DISCUSSION}

$\mathrm{CSDH}$ is among the most common diseases treated by neurosurgeons with an incidence of $8.2-14.1 / 100,000$ person-years $(3,6,10,21,24,26)$. Since burr-hole craniotomy is associated with a low recurrence rate and few complications, it is the primary treatment of choice for $\operatorname{CSDH}(8,26)$. Although it is a frequently occurring disease, there is no accepted standardized treatment for $\mathrm{rCSDH}(2,12)$. For $\mathrm{rCSDH}$ treatment, the Chinese herb gore-san, steroids, and carbazochrome have been used $(37,42)$; moreover, embolization of the middle meningeal artery for treatment was first described by Mandai et al. in 2000 (27).

Karakhan reported the first use of neuroendoscopy for $\mathrm{CSDH}$ treatment in 1988 (19), and a neuroendoscopic

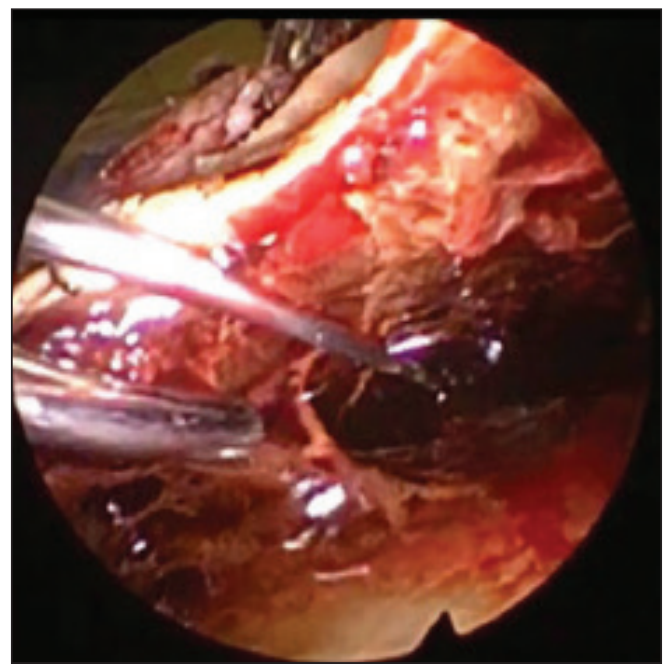

Figure 2: The hematoma is evacuated and septation is incised using a suction tube; irrigation is performed using isotonic isothermal saline solution.

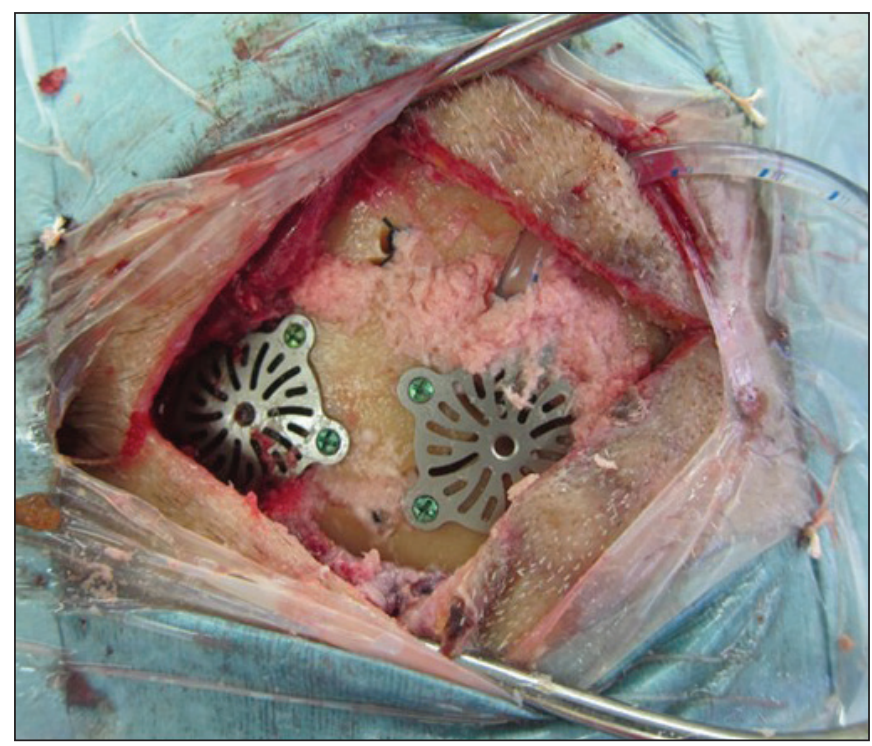

Figure 4: After inserting the draining catheter, the bone flap is fixed with titanium plates and autologous bone dust to cover the bone defect.

technique for acute subdural hematomas was reported more recently $(18,22,25,26,36,37)$. For patients with $\mathrm{rCSDH}$, an endoscopic technique of cutting the trabeculae and separating the membranes in the hematoma cavity was reported $(15,26,29)$. Majovsky et al. described a technique of flexible neuroendoscopic evacuation of CSDH and found a low recurrence rate $(1,26)$.

The advantages of neuroendoscopy include trabeculae and septations visualization, larger exposure for resection of the outer capsule and neomembranes, and proper hemostasis $(18,26)$. This technique can be performed under either local or general anesthesia (18). General anesthesia carries high risks for elderly patients and those with multiple comorbidities; therefore, local anesthesia can be used. Previous studies have 
Ichimura S. et al: Neuroendoscopy for rCSDH

Table II: Result of Patients Who Underwent Neuroendoscopic Removal of Recurrent Chronic Subdural Hematoma with Small Craniotomy

\begin{tabular}{|c|c|c|c|c|c|c|}
\hline Patients & Anesthesia & Septation & $\begin{array}{c}\text { Follow-up } \\
\text { period (months) }\end{array}$ & Regrowth & $\begin{array}{c}\text { Postoperative } \\
\text { seizure }\end{array}$ & Anticonvulsant \\
\hline 1 & Local & + & 8 & - & - & - \\
\hline 2 & General & - & 23 & - & - & - \\
\hline 3 & General & - & 8 & - & Focal (aphasia) & Levetiracetam \\
\hline 5 & General & - & 13 & - & - & \\
\hline 6 & General & - & 16 & - & - & \\
\hline 7 & General & + & 13 & - & - & - \\
\hline 8 & Local & + & 13 & - & - & \\
\hline 12 & General & - & 10 & - & - & \\
\hline 13 & General & + & 10 & - & - & \\
\hline 14 & Local & - & 10 & - & Focal (aphasia) & Lacosamide \\
\hline 15 & Local & + & 10 & - & - & \\
\hline 16 & General & + & 6 & - & Focal (aphasia) & Levetiracetam \\
\hline 17 & Local & + & $6^{*}$ & + & Generalized & Lacosamide \\
\hline
\end{tabular}

*: Followed after the second neuroendoscopic surgery.

recognized a significant correlation between multiseptated or multilayered CSDH and recurrence (40). A small craniotomy allows advantages such as enabling complete hematoma cavity visualization (18), and providing sufficient working space for insertion of the endoscope and manipulation of nonspecialized endoscopy instruments (18).

One of the concerns of neuroendoscopic removal of CSDH is the injury to the brain cortex caused by the endoscope (26). However, there are no reports of increased morbidity as a result of neuroendoscopy. Neurosurgeons must use both hands on the endoscope to avoid injuring the brain cortex $(13,15,29)$. Yan et al. suggest that even though endoscopic surgery allows the removal of the hematoma cavity with a small craniotomy, especially for septated CSDH, there was no difference between neuroendoscopy and burr-hole craniotomy in terms of reduction of rCSDH (41). Large craniotomy and membranectomy with tearing of the inner membrane is used to reduce the recurrence of septated CSDH (40). An enlarging craniotomy is not required, thus minimizing patient discomfort.

The method of tearing the inner membrane for septated CSDH was described by Kayaci et al. (20). Yan et al. hypothesized that the inner membrane is more significant than the outer membrane as a factor in $\mathrm{rCSDH}$ (40). However, cutting and removing the inner membrane might increase cortical damage $(5,40)$.
The incidence of postoperative seizures after the first surgery for CSDH was $1.8 \%-10 \%(23,31,39)$. Hellwig et al. insisted that aggressive membranectomy induced postoperative seizures, brain contusion, and hemorrhage (14). The decomposition of hemoglobin on the cortical surface is strongly associated with epilepsy (39). Intracranial decompression by craniotomy may induce brain injury through sudden negative deceleration, and is epileptogenic $(11,34,35,39)$.

Our study had some limitations being a retrospective case series including patients operated on by one neurosurgeon from a single institute, and comprised a few patients. Further larger, comparative multicenter studies are required to accumulate further evidence of the benefits of neuroendoscopy for recurrent $\mathrm{CSDH}$.

\section{CONCLUSION}

This neuroendoscopic technique with a small craniotomy could be useful for recurrent CSDH because the hematoma and septations can be visualized and evacuated along the entire circumference of the hematoma cavity, and the inner membrane can be incised to allow brain expansion. It can also enable sufficient working space to insert and use neurosurgical instruments to safely and effectively evacuate the hematoma and septations. 


\section{REFERENCES}

1. Almenawer SA, Farrokhyar F, Hong C, Alhazzani W, Manoranjan B, Yarascavitch B, Arjmand P, Baronia B, Reddy K, Murty N, Singh S: Chronic subdural hematoma management: $A$ systematic review and meta-analysis of 34,829 patients. Ann Surg 259:449-457, 2014

2. Alvarez-Pinzon AM, Stein AA, Valerio JE, Delgado V, Escalante JA, Lopez N, Wolf AL: Is subdural peritoneal shunt placement an effective tool for the management of recurrent/chronic subdural hematoma? Cureus 8:e613, 2016

3. Asghar M, Adhiyaman V, Greenway MW, Bhowmick BK, Bates A: Chronic subdural haematoma in the elderly-a North Wales experience. J R Soc Med 95:290-292, 2002

4. Baechli H, Nordmann A, Bucher HC, Gratzl O: Demographics and prevalent risk factors of chronic subdural haematoma: Results of a large single-center cohort study. Neurosurg Rev 27:263-266, 2004

5. Baek HG, Park SH: Craniotomy and membranectomy for treatment of organized chronic subdural hematoma. Korean $\mathrm{J}$ Neurotrauma 14:134-137, 2018

6. Bartek J Jr, Sjåvik K, Kristiansson H, Ståhl F, Fornebo I, Förander P, Jakola AS: Predictors of recurrence and complications after chronic subdural hematoma surgery: A population-based study. World Neurosurg 106:609-614, 2017

7. Boyaci S, Gumustas OG, Korkmaz S, Aksoy K: Endoscopic evacuation of subdural collections. Turk Neurosurg 26:871877, 2016

8. Cenic A, Bhandari M, Reddy K: Management of chronic subdural hematoma: A national survey and literature review. Can J Neurol Sci 32:501-506, 2005

9. Codd PJ, Venteicher AS, Agarwalla PK, Kahle KT, Jho DH: Endoscopic burr hole evacuation of an acute subdural hematoma. J Clin Neurosci 20:1751-1753, 2013

10. Cousseau DH, Echevarria GM, Gaspari M, Gonorazky SE: Chronic and subacute subdural haematoma. An epidemiological study in a captive population. Rev Neurol 32: 821-824, 2001 (Article in Spanish)

11. Englander J, Bushnik T, Duong TT, Cifu DX, Zafonte R, Wright J, Hughes R, Bergman W: Analyzing risk factors for late posttraumatic seizures: A prospective, multicenter investigation. Arch Phys Med Rehabil 84:365-373, 2003

12. Haciyakupoglu E, Yilmaz DM, Kinali B, Arpaci T, Akbas T, Haciyakupoglu S: Recurrent chronic subdural hematoma: Report of 13 cases. Open Med (Wars) 13:520-527, 2018

13. Hamilton MG, Frizzell JB, Tranmer BI: Chronic subdural hematoma: The role for craniotomy reevaluated. Neurosurg 33:67-72, 1993

14. Hellwig D, Heinze S, Riegel T, Benes L: Neuroendoscopic treatment of loculated chronic subdural hematoma. Neurosurg Clin N Am 11:525-534, 2000

15. Hellwig D, Kuhn TJ, Bauer BL, List-Hellwig E: Endoscopic treatment of septated chronic subdural hematoma. Surg Neurol 45:272-277, 1996

16. Huang YH, Yang KY, Lee TC, Liao CC: Bilateral chronic subdural hematoma: What is the clinical significance? Int J Surg 11:544-548, 2013
17. Ichimura S, Fukuchi M, Takahara K, Nakaya M, Yoshida K, Mochizuki Y, Fujii K: Autologous bone dust technique for one burr hole surgery to prevent severe skin depression. Clin Neurol Neurosurg 176:41-43, 2019

18. Ichimura S, Takahara K, Nakaya M, Yoshida K, Mochizuki Y, Fukuchi M, Fujii K: Neuroendoscopic hematoma removal with a small craniotomy for acute subdural hematoma. J Clin Neurosci 61:311-314, 2019

19. Karakhan VB: Experience using intracranial endoscopy in neurologic traumatology. Vestnik Khir Im I Grek 140:102-108, 1988 (Article in Russian)

20. Kayaci S, Kanat A, Koksal V, Ozdemir B: Effect of inner membrane tearing in the treatment of adult chronic subdural hematoma: A comparative study. Neurol Med Chir 54:363373, 2014

21. Kolias AG, Chari A, Santarius T, Hutchinson PJ: Chronic subdural haematoma: Modern management and emerging therapies. Nat Rev Neurol 10:570-578, 2014

22. Kon $H$, Saito A, Uchida $H$, Inoue $M$, Sasaki T, Nishijima $M$ : Endoscopic surgery for traumatic acute subdural hematoma. Case Rep Neurol 5:208-213, 2013

23. Kotwica Z, Brzeiński J: Epilepsy in chronic subdural haematoma. Acta Neurochir (Wien) 113:118-120, 1991

24. Kudo H, Kuwamura K, Izawa I, Sawa H, Tamaki N: Chronic subdural hematoma in elderly people: Present status on Awaji Island and epidemiological prospect. Neurol Med Chir 32: 207-209, 1999

25. Leroy HA, Aboukais R, Reyns N, Bourgeois P, Labreuche J, Duhamel A, Lejeune JP: Predictors of functional outcomes and recurrence of chronic subdural hematomas. J Clin Neurosci 22:1895-1900, 2015

26. Májovský M, Masopust V, Netuka D, Beneš V: Flexible endoscope-assisted evacuation of chronic subdural hematomas. Acta Neurochir 158:1987-1992, 2016

27. Mandai S, Sakurai M, Matsumoto Y: Middle meningeal artery embolization for refractory chronic subdural hematoma. Case report. J Neurosurg 93:686-688, 2000

28. Manickam A, Marshman LA, Johnston R: Long-term survival after chronic subdural haematoma. J Clin Neurosci 34:100104, 2016

29. Mobbs R, Khong P: Endoscopic-assisted evacuation of subdural collections. J Clin Neurosci 16:701-704, 2009

30. Mori K, Maeda M: Surgical treatment of chronic subdural hematoma in 500 consecutive cases: Clinical characteristics, surgical outcome, complications, and recurrence rate. Neurol Med Chir (Tokyo) 41:371-381, 2001

31. Rubin G, Rappaport ZH: Epilepsy in chronic subdural haematoma. Acta Neurochir (Wien) 123:39-42, 1993

32. Santarius T, Kirkpatrick PJ, Ganesan D, Chia HL, Jalloh I, Smielewski P, Richards HK, Marcus H, Parker RA, Price SJ, Kirollos RW, Pickard JD, Hutchinson PJ: Use of drains versus no drains after burr-hole evacuation of chronic subdural haematoma: A randomised controlled trial. Lancet 26:10671073, 2009 
Ichimura S. et al: Neuroendoscopy for rCSDH

33. Santarius T, Lawton R, Kirkpatrick PJ, Hutchinson PJ: The management of primary chronic subdural haematoma: $A$ questionnaire survey of practice in the United Kingdom and the Republic of Ireland. Br J Neurosurg 22:529-534, 2008

34. Seifi A, Asadi-Pooya AA, Carr K, Maltenfort M, Emami M, Bell R, Moussouttas M, Yazbeck M, Rincon F: The epidemiology, risk factors, and impact on hospital mortality of status epilepticus after subdural hematoma in the United States. Springerplus 3:332, 2014

35. Toi H, Kinoshita K, Hirai S, Takai H, Hara K, Matsushita N, Matsubara S, Otani M, Muramatsu K, Matsuda S, Fushimi K, Uno M: Present epidemiology of chronic subdural hematoma in Japan: Analysis of 63,358 cases recorded in a national administrative database. J Neurosurg 128:222-228, 2018

36. Ueba T, Yasuda M, Inoue T: Endoscopic burr hole surgery with a curettage and suction technique to treat traumatic subacute subdural hematomas. J Neurol Surg A Cent Eur Neurosurg 76: 63-65, 2015

37. Uno M, Toi H, Hirai S: Chronic subdural hematoma in elderly patients: Is this disease benign? Neurol Med Chir (Tokyo) 57: 402-409, 2017
38. Weigel R, Schmiedek P, Krauss JK: Outcome of contemporary surgery for chronic subdural haematoma: Evidence based review. J Neurol Neurosurg Psychiatr 74:937-943, 2003

39. Won SY, Konczalla J, Dubinski D, Cattani A, Cuca C, Seifert V, Rosenow F, Strzelczyk A, Freiman TM: A systematic review of epileptic seizures in adults with subdural haematomas. Seizure 45:28-35, 2017

40. Yan K, Gao H, Wang Q, Xu X, Wu W, Zhou X, Xu W, Ye F: Endoscopic surgery to chronic subdural hematoma with neovessel septation: Technical notes and literature review. Neurol Res 8:467-476, 2013

41. Yan K, Gao H, Zhou X, Wu W, Xu W, Xu Y, Gong K, Xue X, Wang $\mathrm{Q}, \mathrm{Na} \mathrm{H}$ : A retrospective analysis of postoperative recurrence of septated chronic subdural haematoma: Endoscopic surgery versus burr hole craniotomy. Neurol Res 39:803-812, 2017

42. Zhang Y, Chen S, Xiao Y, Tang W: Effects of dexamethasone in the treatment of recurrent chronic subdural hematoma. World Neurosurg 105:115-121, 2017 